\title{
Peripheral blood fibrocytes: new information to explain the dynamics of Leishmania infection
}

\author{
Roger Magno Macedo-Silva1', Carina de Lima Pereira dos Santos'1, Vanessa Alvaro Diniz'1, \\ Jorge José de Carvalho ${ }^{2}$, Camila Guerra', Suzana Côrte-Real ${ }^{1 /+}$ \\ 'Laboratório de Biologia Estrutural, Instituto Oswaldo Cruz-Fiocruz, Rio de Janeiro, RJ, Brasil \\ ${ }^{2}$ Departamento de Histologia e Embriologia, Universidade do Estado do Rio de Janeiro, Rio de Janeiro, RJ, Brasil
}

\begin{abstract}
Fibrocytes are important for understanding the progression of many diseases because they are present in areas where pathogenic lesions are generated. However, the morphology of fibrocytes and their interactions with parasites are poorly understood. In this study, we examined the morphology of peripheral blood fibrocytes and their interactions with Leishmania (L.) amazonensis. Through ultrastructural analysis, we describe the details of fibrocyte morphology and how fibrocytes rapidly internalise Leishmania promastigotes. The parasites differentiated into amastigotes after $2 \mathrm{~h}$ in phagolysosomes and the infection was completely resolved after $72 \mathrm{~h}$. Early in the infection, we found increased nitric oxide production and large lysosomes with electron-dense material. These factors may regulate the proliferation and death of the parasites. Because fibrocytes are present at the infection site and are directly involved in developing cutaneous leishmaniasis, they are targets for effective, non-toxic cell-based therapies that control and treat leishmaniasis.
\end{abstract}

Key words: fibrocyte - Leishmania (L.) amazonensis - cell biology

Fibrocytes are hematopoietic cells that are characterised by the co-expression of leukocyte cell surface molecules, CD45 or CD14 and extracellular matrix proteins, such as collagen type I and type III (Bucala et al. 1994). In addition to these markers, fibrocytes may express inflammatory tracers that are similar to those in macrophages, such as adhesion proteins CD11b, CD11c and CD11d and antigen presentation molecules, as major histocompatibility complex class I and class II, CD80 and CD86 (Chesney et al. 1997). Fibrocytes express hematopoietic markers, such as CD34, that are not present on macrophages. Fibrocytes also distinguish themselves from macrophages by their spindle-shaped morphology and cytoplasmic extensions, which adhere to the substrate. As previously reported (Chesney et al. 1998), fibrocytes synthesise collagen and glycosaminoglycans; however, compared with fibroblasts, fibrocytes produce more collagen $\mathrm{V}$ and less collagen I, III and IV. Likewise, the profile of glycosaminoglycan production in fibrocytes is distinct from fibroblasts, as fibrocytes are characterised by high levels of perlecan, versican and hyaluronic acid and low biglycan and decorin (Pilling et al. 2009, Reilkoff et al. 2011). Both fibroblasts and fibrocytes have fusiform morphology, but hematopoietic inflammatory markers are only expressed in fibrocytes. However, the differentiation of this cellular group within tissues is complicated.

doi: 10.1590/0074-0276130247

Financial support: FIOCRUZ, CNPq, FAPERJ

+ Corresponding author: scrf@ioc.fiocruz.br

Received 6 May 2013

Accepted 24 September 2013
In many diseases, fibrocytes are associated with wound healing and fibrosis (Chesney et al. 1997, Abe et al. 2001, Moore et al. 2005, Ishida et al. 2007). Moreover, fibrocytes are involved in the initial inflammation and remodelling processes (Nihlberg et al. 2006) and host interactions with microorganisms (Grab et al. 1999). Despite the growing number of reports describing fibrocyte contributions to inflammation during various diseases (Chesney et al. 1998, Quan et al. 2004, Wang et al. 2007, Reilkoff et al. 2011, Peng \& Herzog 2012), the function of fibrocytes in peripheral blood and other tissues during normal conditions and pathologies caused by infectious agents is unclear. Leishmania spp is parasites that belong to the Kinetoplastida family and they are the causative agents of cutaneous leishmaniasis, which is responsible for high morbidity in the Americas and is included in the World Health Organization's list of neglected diseases. Considering the characteristics of natural inoculation by the sandfly and the Leishmania lesions caused by infection, where there is a large supply of blood cells to the skin and the need for restoration of the extracellular matrix (de Almeida et al. 2003, Gontijo $\&$ de Carvalho 2003), it can be assumed that fibrocytes may participate in the initial inflammatory response to infection by parasites of the genus Leishmania. As fibrocytes are found in the peripheral blood and demonstrate the ability to rapidly migrate to damaged tissues, it is possible that, as proposed by Grab et al. (2004), they may play an important role in establishing Leishmania infections, which induce a T-helper 2 immune response and interleukin-10 production, aiding in the establishment of infection. Thus, an assessment of the fibrocyte interactions with Leishmania (Leishmania) amazonensis promastigotes can be a good model for characterising fibrocyte functions and may lead to the proposal of 
methods that are more efficient and less toxic for leishmaniasis prophylaxis.

\section{MATERIALS AND METHODS}

Mice - The peripheral blood fibrocytes were obtained from mice. The animals were housed at the Centre for Laboratory Animal Breeding of the Oswaldo Cruz Foundation (Fiocruz) and handled in accordance with the provisions set forth by the Ethical Committee of Fiocruz for the use of animals (resolution CEUA-242/99) under the license LW 2/12.

Fibrocyte cell culture - The cultures were maintained under the conditions described by Bucala et al. (1994), with some modifications described below. Peripheral blood mononuclear (PBM) cells were isolated by gradient centrifugation in Ficoll-Histopaque ${ }^{\circledR} 1077$ (SigmaAldrich Inc, St. Louis, MO, USA). The cells were incubated in $5 \% \mathrm{CO}_{2}$ and $37^{\circ} \mathrm{C}$ in a serum-free Dulbecco's Modified Eagle's Medium (DMEM)/F12 medium (Sigma-Aldrich) supplemented with $0.15 \%$ L-glutamine, 100 $\mathrm{U} / \mathrm{mL}$ penicillin and $100 \mu \mathrm{g} / \mathrm{mL}$ streptomycin (SigmaAldrich). The cells were maintained under these conditions for 21 days with medium changes every five days to completely purify the culture.

Fibrocyte characterisation - Mononuclear cells were obtained from peripheral blood, washed in phosphate buffered saline (PBS) and incubated for $20 \mathrm{~min}$ at $4^{\circ} \mathrm{C}$ in a solution that blocked the $\mathrm{Fc}$ receptors $(\mathrm{FcR})(10 \%$ foetal calf serum and $10 \%$ sheep serum in PBS). The cells were then incubated with a rat anti-CD45 $\operatorname{IgG} 2 \mathrm{a}$ monoclonal primary antibody (Santa Cruz Biotechnology, Inc, Heidelbergh, Germany) and an anti-rat IgG fluorescein isothiocyanate (FITC)-conjugated secondary antibody (Sigma-Aldrich). The cells were fixed in $1 \%$ paraformaldehyde (PFA), permeabilised with $0.2 \%$ saponin (Sigma-Aldrich) and incubated with a rabbit anti-heat shock protein (HSP)47 primary antibody (Santa Cruz Biotechnology). After intracellular labelling, the cells were washed, incubated with anti-rabbit solid phase reaction board-conjugated secondary antibody (Southern Biotech, Birmingham, AL, USA), washed again and post-fixed with $2 \%$ PFA. A total of 50,000 data points were acquired using a FACSCalibur flow cytometer (Becton \& Dickinson Co, Franklin Lakes, NJ, USA) and analysed with Summit software (Dako Colorado Co, Fort Collins, CO, USA).

Epifluorescence analysis of fibrocyte primary culture - The fibrocytes were plated on cover slips, fixed with $4 \%$ PFA and incubated overnight at $4^{\circ} \mathrm{C}$ with a rat anti-CD45 IgG2a primary antibody diluted in $2 \%$ bovine serum albumin (BSA) in PBS. The coverslips were washed, permeabilised with $0.5 \%$ Triton X-100 and incubated with a rabbit anti-HSP47 primary antibody. The coverslips were then incubated for $1 \mathrm{~h}$ at $37^{\circ} \mathrm{C}$ in a humid chamber with anti-rat IgG FITC-conjugated and anti-rabbit IgG tetramethylrhodamine-conjugated secondary antibodies (Sigma-Aldrich). The coverslips were washed with $2 \%$ BSA in PBS and incubated for $5 \mathrm{~min}$ at room temperature (RT) with $10 \mu \mathrm{g} / \mathrm{mL}$ 4',6-diamidino2-phenylindole (Sigma-Aldrich). After washing in PBS, the coverslips were mounted on slides with PBS, $\mathrm{pH}$ 7.2, containing 2.5\% 1,4-diazabicyclo-(2,2,2)-octanetriethylenediamine and $50 \%$ glycerol. The slides were analysed on a Zeiss Axioplan microscope equipped with epifluorescence. The fluorescence analysis used a $63 \mathrm{X}$ objective for a blinded assessment that was performed by two independent observers.

Parasites - L. (L.) amazonensis MHOM/BR/77/ LTB0016 strain promastigotes were cultured on biphasic blood agar (Novy and McNeal, modified by Nicolle) or in a liquid medium Schneider's insect medium (SigmaAldrich) supplemented with $10 \%$ foetal bovine serum (FBS) at $26^{\circ} \mathrm{C}$. The cultures were grown in vitro to stationary phase, at which the infectious metacyclic promastigotes were enriched (Sacks et al. 1985, Rogers et al. 2004). To maintain their virulence, the parasites were only passaged up to five times in vitro.

Infection kinetics - The fibrocytes were infected with $L$. (L.) amazonensis promastigotes in DMEM/F12 serum-free medium in $5 \% \mathrm{CO}_{2}$ and $37^{\circ} \mathrm{C}$. After $2 \mathrm{~h}$ of incubation, the cultures were washed and the infection kinetics were determined at $2 \mathrm{~h}, 6 \mathrm{~h}, 24 \mathrm{~h}, 48 \mathrm{~h}$ and $72 \mathrm{~h}$ and seven days. To analyse the infection kinetics, coverslips with 300 cells each were stained with Giemsa and mounted individually on glass slides; two independent observers quantified the infected cells under the $63 \mathrm{X}$ objective of a light microscope (Zeiss Axioplan 2). The infected culture supernatants were collected and stored to later determine the nitric oxide (NO) level.

Scanning electron microscopy - Fibrocytes infected with $L$. (L.) amazonensis were fixed at $2 \mathrm{~h}, 6 \mathrm{~h}$ and $24 \mathrm{~h}$ post-infection with $2.5 \%$ glutaraldehyde (GA) in $0.1 \mathrm{M}$ sodium cacodylate $(\mathrm{pH} 7.2)$ for $1 \mathrm{~h}$ at $4^{\circ} \mathrm{C}$. After washing, the cells were post-fixed with $1 \%$ osmium tetroxide $\left(\mathrm{OsO}_{4}\right)$ for $1 \mathrm{~h} 4^{\circ} \mathrm{C}$. The cultures were dehydrated in a ketone series $(30 \%, 50 \%, 70 \%, 90 \%$ and $100 \%)$, dried in a critical point apparatus 030 (Balzers), metallised (Desk IV) (Denton Vacuum LLC, Moorestown, NJ, USA) and analysed with a scanning electron microscope (Jeol JSM-6390LV) on the Rudolf Barth Electron Microscopy Platform at the Fiocruz.

Transmission electron microscopy - The fibrocytes infected with $L$. (L.) amazonensis were fixed at $2 \mathrm{~h}$ postinfection with $2.5 \%$ GA diluted in $0.1 \mathrm{M}$ sodium cacodylate, $\mathrm{pH} 7.2$, for $1 \mathrm{~h}$ at $4^{\circ} \mathrm{C}$. The cells were post-fixed with $1 \% \mathrm{OsO}_{4}$ for $1 \mathrm{~h}$ at $4^{\circ} \mathrm{C}$. The cells were then dehydrated in a ketone series and embedded in PolyBed 812 resin. After the polymerisation, ultrathin sections were prepared (Reichert ultramicrotome Omu3), collected on 300 -mesh grids, stained with $5 \%$ uranyl acetate $/ 1 \%$ lead citrate and analysed on a transmission electron microscope (Jeol JEM-1011) on the Rudolf Barth Electron Microscopy Platform at the Fiocruz.

Dosage of nitrite - To evaluate NO production in primary cultures of infected fibrocytes, $100 \mu \mathrm{L}$ infected cell supernatants was incubated with $100 \mu \mathrm{L}$ Griess reagent $[0.1 \%$ N-(1-naphthyl)ethylenediamine dihydrochloride (Sigma-Aldrich), $1 \%$ sulfanilamide (Sigma-Aldrich) and $5 \%$ phosphoric acid (Sigma-Aldrich)] at RT. The standard 
curve was obtained with sodium nitrite (Sigma-Aldrich) and the readings were taken at $550 \mathrm{~nm}$ on a micro-ELISA reader (Molecular Device, New Milton, WV, USA).

Statistical analysis - The statistical significance was calculated with a nonparametric one-way analysis of variance test and a p value of $<0.05$ was considered significant.

\section{RESULTS}

Isolation of peripheral blood fibrocytes - The identification of fibrocytes has generated numerous questions, mainly because there is not a specific marker that differentiates this cell type from fibroblasts, monocytes or macrophages. To study the fibrocytes in BALB/c mice, we analysed the monolayers of mononuclear cells that

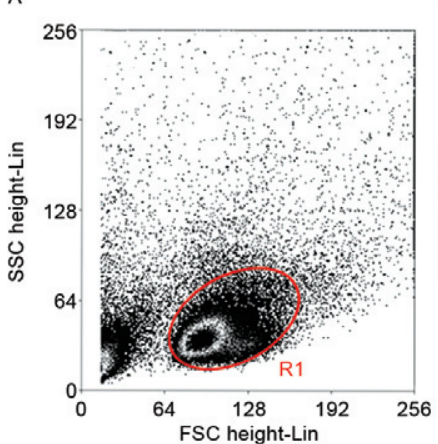

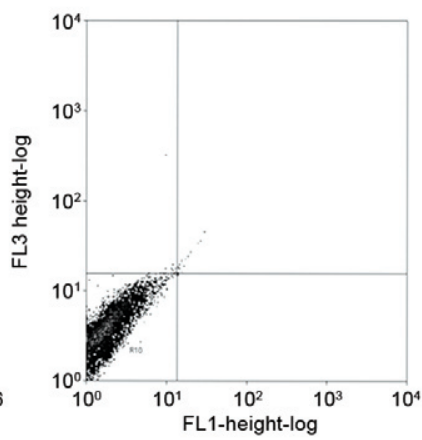

C

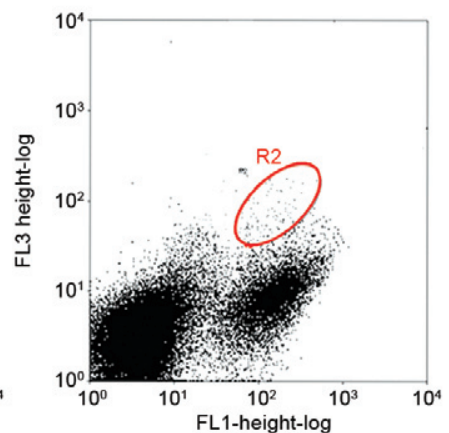

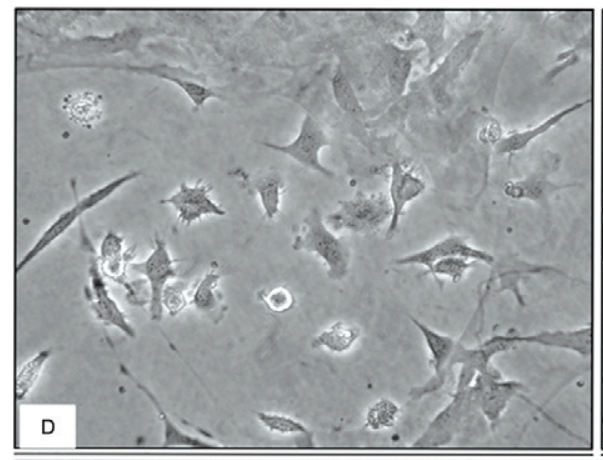
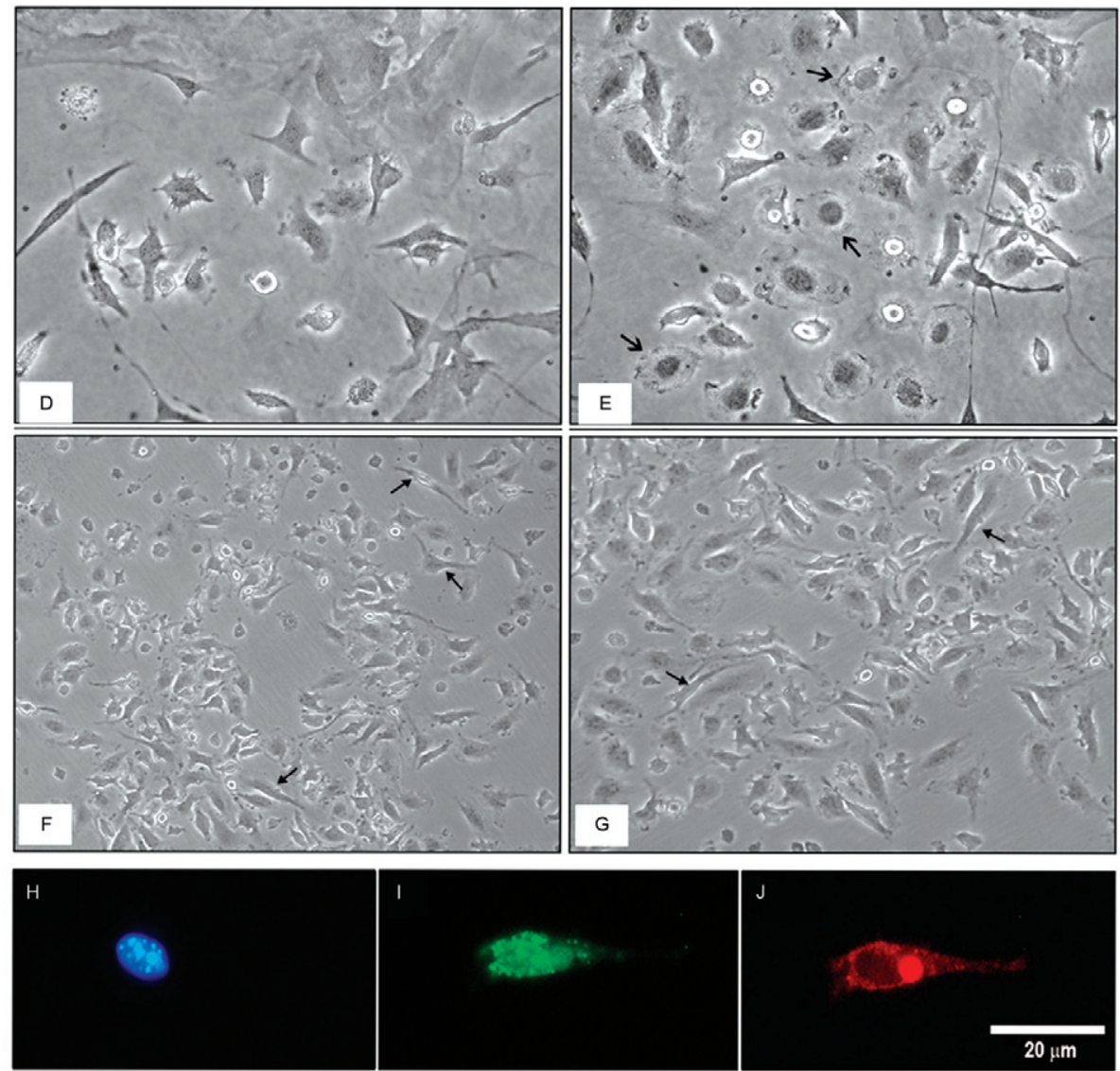

Fig. 1: an evaluation of fibrocytes in the peripheral blood of BALB/c mice. A: dot plot [forward scatter (FSC) and side scatter (SSC)] showing retrograde (R1) marking of heat shock protein (HSP) $47^{+} / \mathrm{CD} 45^{+}$; B: dot plot of the negative control in FL1/FL3; C: Dot plot identification of fibrocytes $\left(\mathrm{CD} 45^{+} / \mathrm{HSP}^{+}\right)$in the double-positive region (R2) for FL1 \{fluorescein isothiocyanate [(FITC)-CD45] and FL3 (HSP47-SPRD)\}; D, E: Fibrocyte primary cultures were analysed after 21 days with phase-contrast light microscopy. Elongated cells with cytoplasmic projections and a few rounded cells (arrow) are shown at 40X magnification; F, G: fibrocyte cultures with large numbers of elongated cells with the cytoplasmic projections that are characteristic of this cell type (arrow) at 10X magnification; H: 4',6-diamidino-2-phenylindole-stained nucleus in blue; I: fibrocytes identified by the immunostaining of CD45 (FITC) at the cell surface in green; J: HSP47 (tetramethylrhodamine) in red distributed along the cytoplasm. 
were isolated from peripheral blood and we observed cells expressing both CD45 at the cell surface and HSP47 in the cytoplasm within the endoplasmic reticulum (ER). The double staining allowed fibrocytes to be identified within the group of PBM cells removed from BALB/c mice; fibrocytes comprised approximately $0.3 \%$ of the analysed cells (Fig. 1A-C).

After identifying the peripheral blood fibrocytes, these cells were initially grown in the presence of FBS. Under these culture conditions, the fibrocytes exhibited cytoplasmic extensions and diverse rounded and spindle morphologies within the same culture. When the cells were cultured in FBS-free medium containing only Lglutamine, they multiplied and predominantly exhibited an elongated morphology, with several cytoplasmic projections. Cultures with these characteristics maintained a homogeneous morphology and exhibited higher rates of proliferation than cultures grown in medium containing FBS (Fig. 1D-G).

Fibrocyte characterisation - To determine whether the in vitro culture conditions would lead to changes in fibrocyte HSP47 and CD45 expression, we performed a phenotypic analysis after cultivation for 21 days. We observed that $100 \%$ of the fibrocytes were stained for

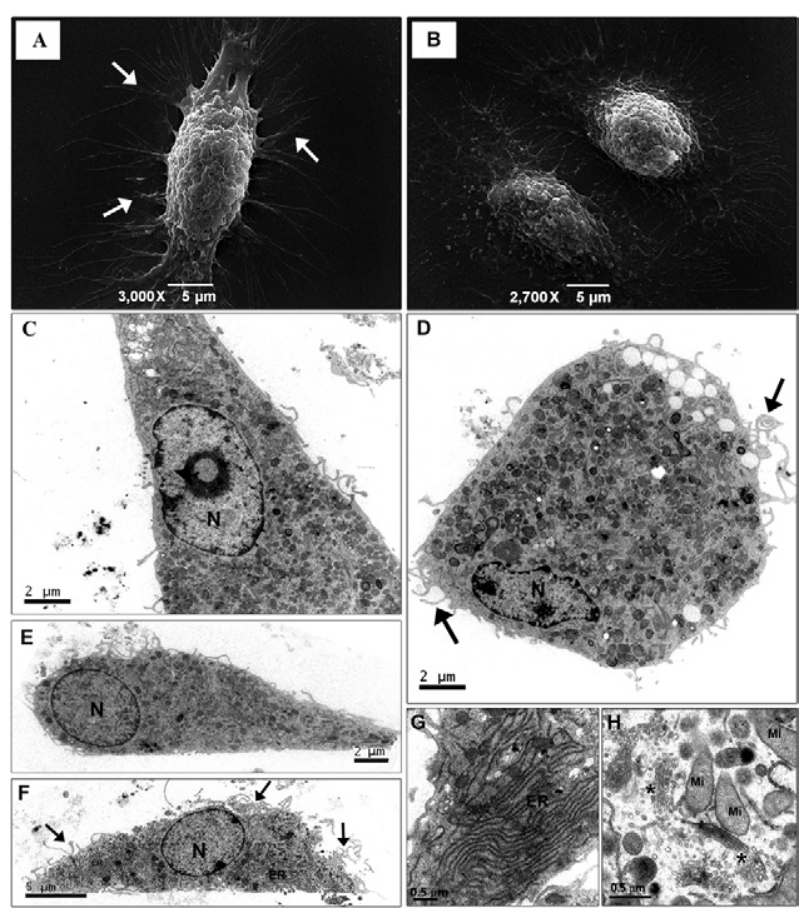

Fig. 2: morphological analysis of fibrocytes. A: scanning electron micrographs showing filopodia on the cell surface (arrow) and the voluminous central region dividing fibrocytes (B); C: longitudinal section of a fibrocyte showing the nucleus $(\mathrm{N})$ with heterochromatin, euchromatin and the central nucleolus; D: a cross-section showing a cytoplasm rich in organelles and filopodia (arrows) at the cellular surface; E, F: the fibrocyte endoplasmic reticulum (ER) is distributed throughout the cytoplasm. A spherical $\mathrm{N}$ and filopodia are present (arrows); G, H: high magnification images of the ER, mitochondria (Mi) and Golgi apparatus (asterisks).
CD45 and HSP47, which indicated that after this period we had obtained a pure fibrocyte culture (Fig. 1H-J).

A major challenge for studying fibrocytes during wound healing and fibrosis is the difficulty in distinguishing fibrocytes from other cell types. The cellular ultrastructure of fibrocytes was analysed to differentiate their morphology. The fibrocytes had a spindle-shaped morphology with numerous cytoplasmic projections and a voluminous central region, where a nucleus was evident (Fig. 2A, B). These cells had rounded nuclei with dense peripheral chromatin and usually a single central nucleolus (Fig. 2C) and they contained a large number of organelles, which were mostly mitochondria (Fig. 2D) and rough ER that was elongated with low-profile dilatation (Fig. 2E-G). The fibrocytes were characterised by the presence of more than one Golgi apparatus, with well-defined cisternae and high concentrations of vesicles (Fig. 2H).

Fibrocyte infection - Although the important roles of fibroblasts and macrophages in various diseases are well known, the role of fibrocytes is less clear (Rosado \& Rodriguez-Sosa 2011, Scholten et al. 2011, Field et
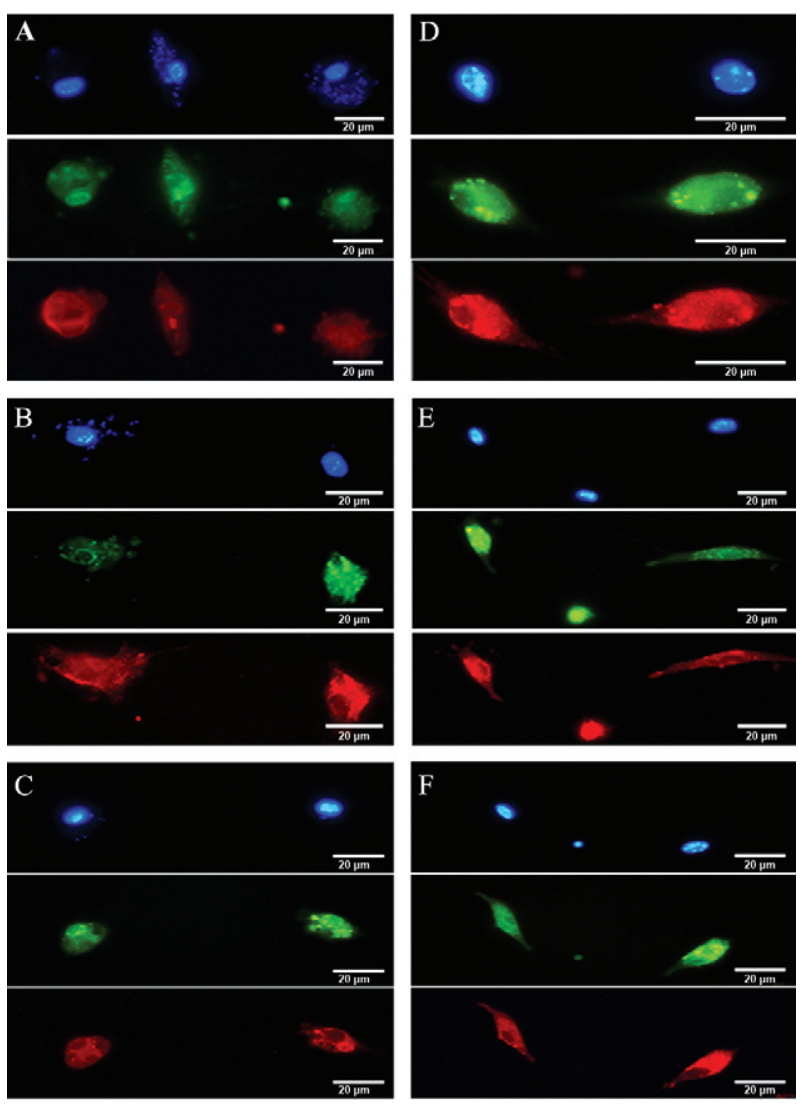

Fig. 3: the fibrocyte phenotypes during Leishmania (Leishmania) amazonensis infection were detected with fluorescence microscopy. A: cells stained with 4,6-diamidino-2-phenylindole (DAPI) (blue), CD45luorescein isothiocyanate and heat shock protein 47-tetramethylrhodamine $2 \mathrm{~h}$ post-infection. The nucleus and kinetoplast are stained with DAPI; B: at $6 \mathrm{~h}$ post-infection; C: at $24 \mathrm{~h}$ post-infection; D: at $48 \mathrm{~h}$ postinfection, no parasites are present; E: at $72 \mathrm{~h}$ post-infection; F: seven days post-infection, CD45 and HSP47 expression is unchanged. 
al. 2012, Garibaldi et al. 2013). We studied the in vitro interactions of peripheral blood fibrocytes and $L$. (L.) amazonensis promastigotes and we found that the cells internalised the parasites. Internalisation did not lead to fibrocyte differentiation, as we did not observe changes in HSP47 or CD45 expression during infection (Fig. 3A-F). Initially, large numbers of parasites attached to the fibrocyte plasma membrane and, subsequently, the parasites remained in narrow parasitophorous vacuoles until they were fully digested (Fig. 4A-F). The quantitative evaluation of infection showed that after $2 \mathrm{~h}, 50 \%$ of the fibrocytes had parasites within the parasitophorous vacuoles and $30 \%$ of the fibrocytes contained parasites after $6 \mathrm{~h}$. There was a significant reduction in the percentage of infected fibrocytes at longer post-infection time periods; only $2 \%$ or $1 \%$ of the fibrocytes contained parasites at $24 \mathrm{~h}$ and $48 \mathrm{~h}$ post-infection, respectively.
After 72 h, only empty vacuoles, but no whole parasites were observed in infected fibrocytes (Fig. 4G).

Because the fibrocytes were able to terminate parasite infections, we speculated that these cells produced NO. Macrophage NO production is a classical defense mechanism that is used to resolve Leishmania infection (von Stebut et al. 2002, Portillo et al. 2012). Thus, the early (72 $h$ post-infection) destruction of parasites by NO in fibrocytes was studied. Within $2 \mathrm{~h}$ after promastigote infection, there was a significant increase in NO production by fibrocytes $(16 \mu \mathrm{mol})$; this increase was approximately three times higher than in the non-infected control (5.5 $\mu \mathrm{mol})$. However, at $6 \mathrm{~h}$ post-infection, NO production was lower than in the non-infected cultures $(3.3 \mu \mathrm{mol})$. After $24 \mathrm{~h}$, NO production was gradually reduced and no differences were observed between the control and infected cultures at subsequent time points (Fig. 5).
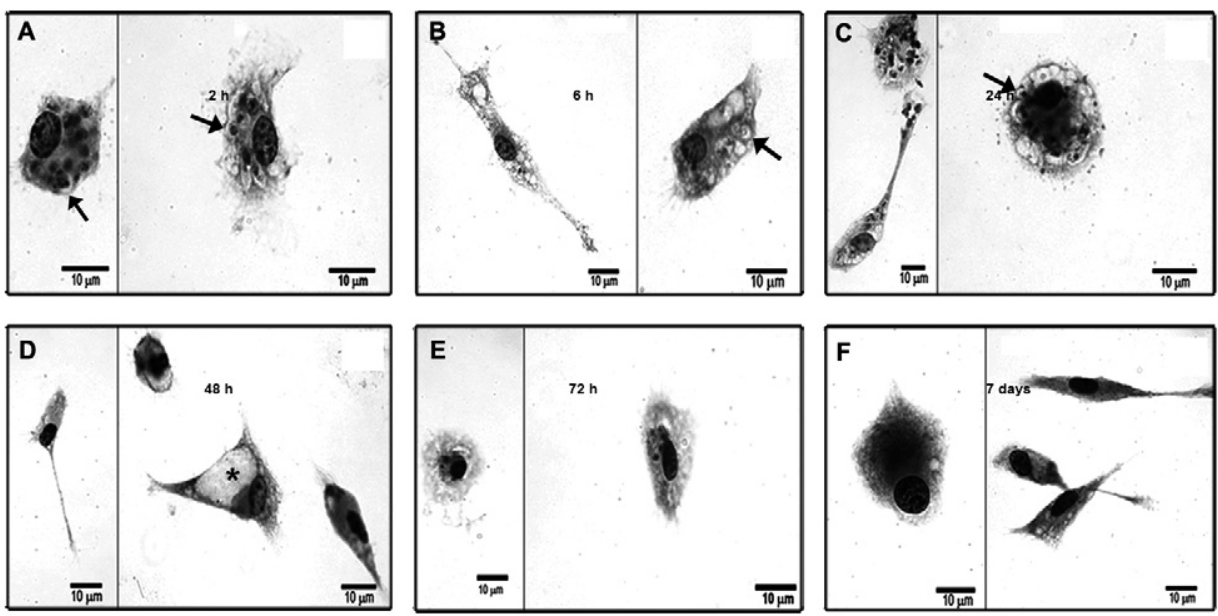

G

Percentual of fibrocytes infection by L. (L.) amazonensis promastigotes

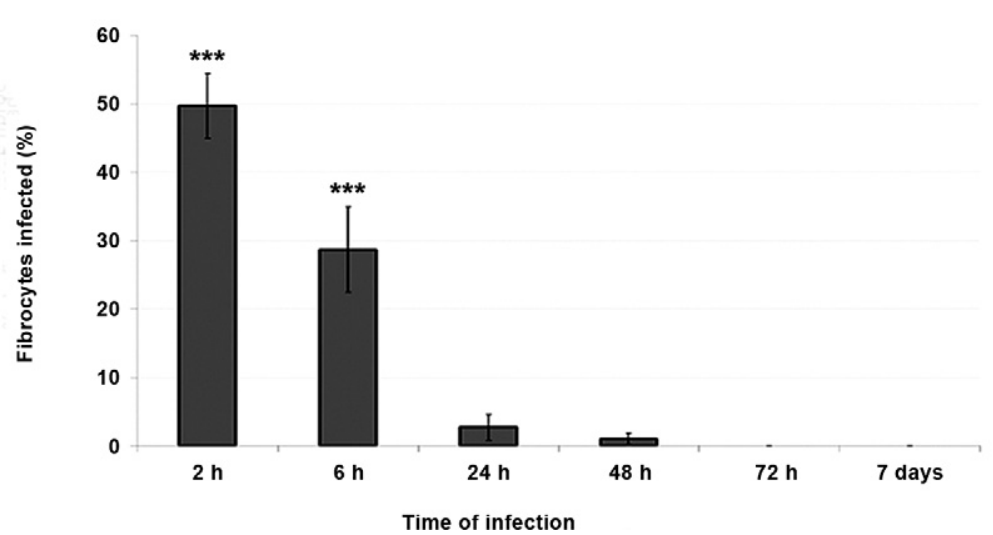

Fig. 4: infection kinetics of the fibrocyte with Leishmania (Leishmania) amazonensis. A: fibrocytes were stained with Giemsa $2 \mathrm{~h}$ after infection with $L$. (L.) amazonensis promastigotes; the parasites were present in parasitophorous vacuoles (arrows); B: after $6 \mathrm{~h}$ of infection, intact parasites were observed in dilated parasitophorous vacuoles (arrows); C: at $24 \mathrm{~h}$ post-infection, few parasites were observed (arrows); D, E: at $48 \mathrm{~h}$ and $72 \mathrm{~h}$ post-infection, the parasitophorous vacuoles were empty or contained debris (asterisk); F: after seven days of infection, no intracellular parasites were observed; G: a quantitative analysis of the infection. Parasite counts were performed in cells grown on coverslips, stained with Giemsa and analysed with light microscopy (63X objective) in three independent experiments. Asterisks mean $\mathrm{p}<0.001$. 
Morphological analysis of infection - The interaction of fibrocytes and parasites has not been fully elucidated, but the characterisation of this interaction is essential for understanding the pathogenesis of and immune response to Leishmania infection. We performed an ultrastructural analysis of the interaction between fibrocytes and L. amazonensis. Large numbers of promastigotes adhered to fibrocytes via the parasite bodies and flagella (Fig. 6A). Parasites in endosomes (Fig. 6B) differentiated into amastigotes; some parasites divided within the narrow parasitophorous vacuoles (Fig. 6C). In contrast, the amastigotes were degraded, as shown by the rarefaction of cytoplasm and extreme vacuolisation (Fig. 6D, E). In the cytoplasm of infected fibrocytes, dilated and elongated endosomes containing electron-dense material were observed during the first $72 \mathrm{~h}$ of infection (Fig. $6 \mathrm{~F}$ ). Moreover, electron-dense material was observed within parasitophorous vacuoles containing degraded parasites (Fig. 6G, H). After seven days of infection, the fibrocytes recovered their cellular integrity and showed a morphology that was similar to the control cultures, which indicated that the infection was resolved.

\section{DISCUSSION}

Fibrocytes share morphological and phenotypic similarities with monocytes, macrophages and fibroblasts and many different markers have been used to distinguish fibrocytes from these cell types (Bucala et al. 1994, Aiba \& Tagami 1997, Wang et al. 2007, Pilling et al. 2009). We have identified fibrocytes by their intracellular HSP47; a 47-kDa collagen-specific molecular chaperone found in skin fibroblast with plays an essential role in collagen I biosynthesis (Kuroda \& Tajima 2004) and cell surface CD45 expression. The double HSP47/CD45 marker was important for detecting fibrocytes in the PBM cells of from healthy mice. Data from the literature indicate that fibrocytes differentiate from monocytes. It is possible that circulating $\mathrm{CD}_{1} 4^{+}$peripheral blood monocytes differentiate into fibrocytes prior to their ar-

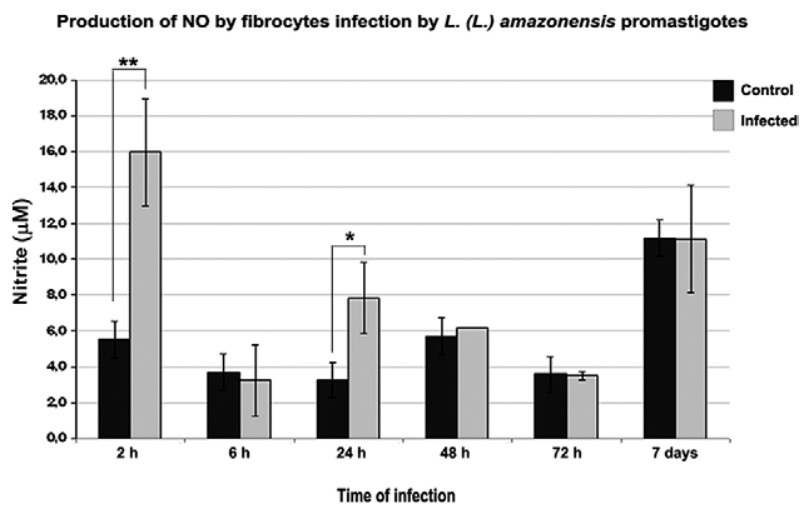

Fig. 5: quantitative analysis of nitric oxide production in fibrocytes infected with Leishmania (Leishmania) amazonensis. Nitrite in the culture supernatants was measured by the Griess method. The average values were obtained from three independent experiments. $*$ : $p<$ $0.05 ; * * \mathrm{p}<0.01$. rival in damaged tissue (Abe et al. 2001, Pilling et al. 2003). However, we detected differentiated fibrocytes within the peripheral blood monocyte populations of healthy mice. From these data, it is clear that fibrocytes are of mononuclear origin and is possible that $\mathrm{HSP}_{4} 7^{+} /$ CD $45^{+}$fibrocytes in peripheral blood share a common bone marrow-derived precursor with other circulating monocytes. This study led us to believe is a possible explanation for the origin of fibrocytes, which allows them to be differentiated from monocytes, macrophages and fibroblasts (Fig.7). Fibrocytes produce extracellular matrix proteins (Bucala et al. 1994, Wang et al. 2007), yet this feature may be secondary or dependent on the occurrence of specific stimuli. Even considering molecules associated with the production of type I collagen, such as prolyl-4-hydroxylase, procollagen I (Aiba \& Tagami 1997, Andersson-Sjöland et al. 2008) and HSP47, it is possible your field of operation resembles that of other leukocytes, could play an important role in targeting the immune response, even associated with autoimmunity or mediated by microorganisms and in the maintenance of tissue homeostasis.

Research has identified the fibrocytes in several pathologies (Schimidt et al. 2003, Nihlberg et al. 2006, Bucala 2008, Kisseleva et al. 2011, Peng \& Herzog 2012), but few reports have mentioned the direct interaction of pathogens with fibrocytes (Peters et al. 1995, Chesney et al. 1998, Grab et al. 1999, Balmelli et al. 2005). Using the double marker HSP47/CD45, we detected fibrocytes at the sites of parasitic infection (data not shown) and analyse the response of fibrocytes to in vitro infection with $L$. (L.) amazonensis. In this process, the parasites appeared to be closely related to small cytoplasmic extensions, suggesting that receptors are associated with adhesion, thus maintaining the connection between the parasite and the cell for a sufficient period of time for endocytosis to occur. There is a clear similarity with the infection of peritoneal macrophages and fibroblasts by several species of Leishmania (Côrte-Real et al. 1988, Bogdan et al. 2000, Noben-Trauth et al. 2003, Hespanhol et al. 2005); these events are mediated by binding to molecules present on the surface of the parasite, lipophosphoglycan and GP63 and to receptors present on the surface of the host cell, such as CR3, CR1 and mannosyl fucosyl receptors, among others (Laskay et al. 2003, Pilling et al. 2006, Liese et al. 2008, Ueno \& Wilson 2012).

The initial interaction of macrophages with Leishmania reflects a combination of strategies that allow this intracellular parasite to establish itself inside a host cell that is devoid of microbicidal activity and the cell, in turn, employs strategies aimed at efficiently phagocytosing and killing the aggressor. Some research groups have studied different receptors present in fibrocytes, including FcR gamma and Toll-like receptors TLRs (Balmelli et al. 2007, von Stebut 2007), which are also found in other groups of professional phagocytes, such as monocytes, macrophages and neutrophils (Cunningham 2002, Laskay et al. 2003, Naderer \& McConville 2008). These receptors may be involved in the interaction of intracellular parasites such as Leishmania with fibrocytes. Thus, we must expand our knowledge regarding 
which receptors are involved in the interaction between Leishmania and fibrocytes, studies of which have been underway for decades in macrophages and neutrophils, to better understand the relationships of this parasite with the microenvironment formed in the skin and other organs where it resides.

Macrophages infected with $L$. (L.) amazonensis have large parasitophorous vacuoles containing amastigotes, which can withstand the acidic environment and the action of hydrolases; after multiplication, the amastigotes disrupt the cell membrane and are released into the ex- tracellular medium (Burchmore \& Barrett 2001, Späth et al. 2003, Opperdoes \& Coombs 2007). Analysis of fibrocytes infected with $L$. (L.) amazonensis showed that the promastigotes initially remained in narrow parasitophorous vacuoles, where they matured into amastigotes. These parasites subsequently initiated the process of cell division, but their multiplication was insufficient to establish infection. In macrophages, lysosomes with peroxidases are fused to parasitophorous vacuoles containing Leishmania in an attempt to eliminate the parasite (Liese et al. 2008). In infected fibrocytes, several lyso-
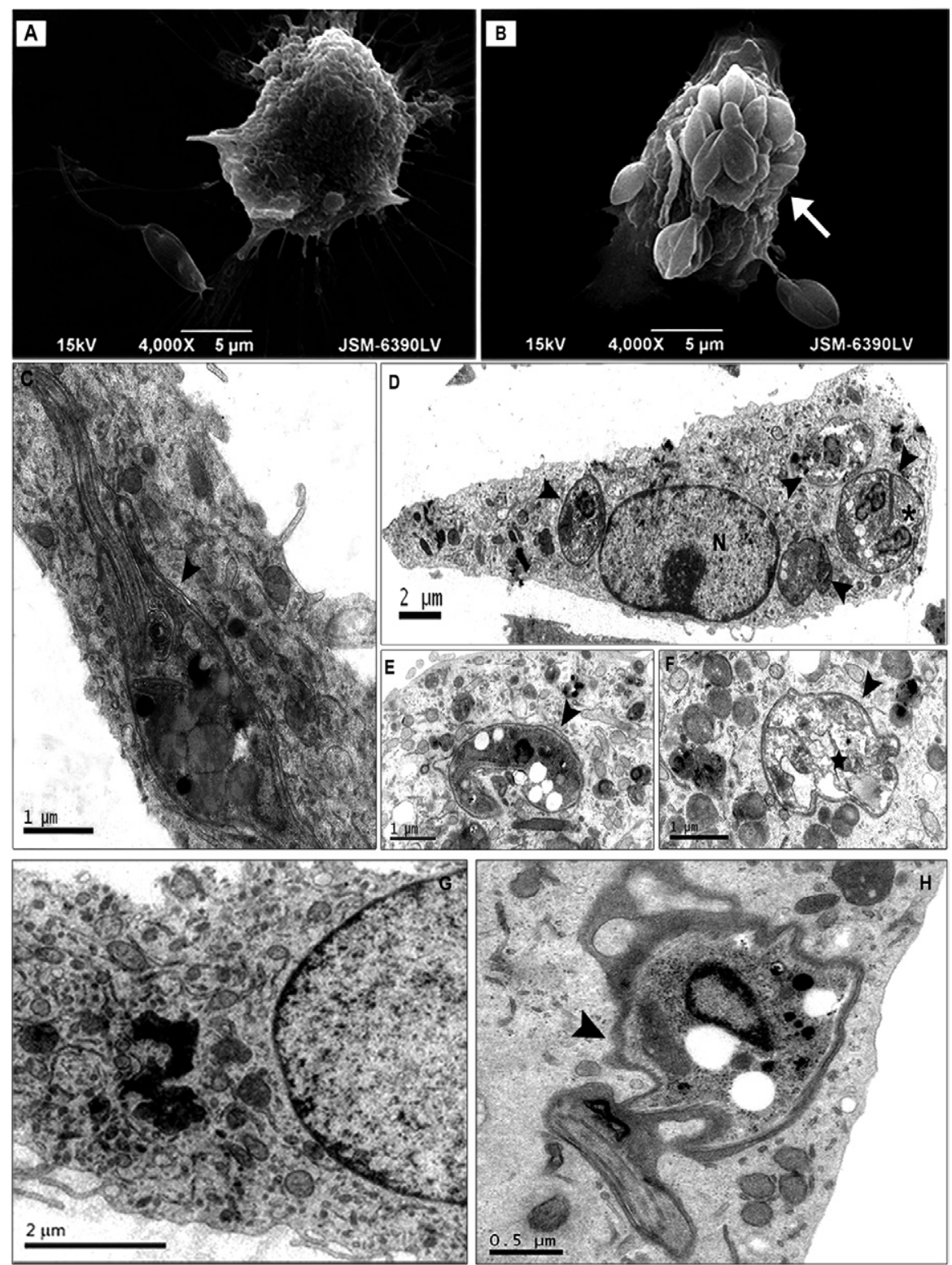

Fig. 6: ultrastructural analysis of fibrocytes infected with Leishmania (Leishmania) amazonensis. A, B: scanning electron micrographs showing large numbers of Leishmania (L.) amazonensis promastigotes interacting with fibrocytes via the parasite body or flagellum (arrows): C: longitudinal section of a promastigote within a narrow parasitophorous vacuole showing the flagellum, flagellar pocket and kinetoplast; D: a fibrocyte with thin, elongated morphology containing dividing amastigotes in the narrow parasitophorous vacuoles (asterisk); E: vacuoles with a dying amastigote; F: dilatation of the endoplasmic reticulum and reduction of the cytoplasm; G: fibrocyte with a large lysosome near the nucleus (arrows); H: fibrocyte containing promastigotes surrounded by electron-dense material within the parasitophorous vacuole (head arrows). 


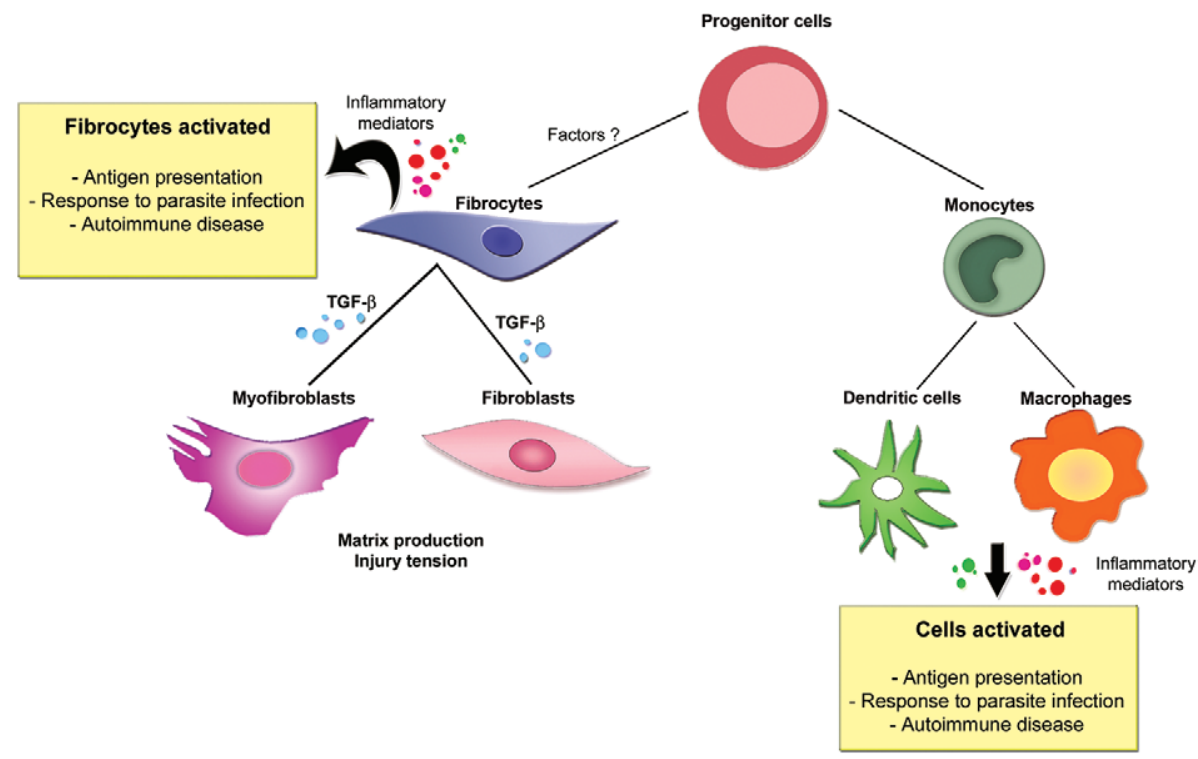

Fig. 7: schematic illustration of fibrocytes and monocytes originating from a single precursor in bone marrow. Cell groups that originate during the differentiation of fibrocytes and monocytes determined by different molecules. TGF: transforming growth factor.

somes and large endosomes containing electron-dense material were observed. The lysosomal enzymes of fibrocytes are unknown, but our data suggested that they actively eliminated parasites in two of its life stages and prevented $L$. (L.) amazonensis infection. This recovery did not occur in the macrophages; instead, the parasite resisted the hydrolytic enzymes and established infection (Diefenbach et al. 1999, Lodge et al. 2006).

We speculate that fibrocytes produced NO because the leishmanicidal action of NO controls Leishmania sp. multiplication in infected macrophages (Cunningham 2002, Mukbel et al. 2007). Although NO is known to control their infection, some protozoa have mechanisms that interfere with NO production in the host cell (Wanasen et al. 2007). Fibrocytes produced large amounts of $\mathrm{NO}$ in the first $2 \mathrm{~h}$ after infection; the increased $\mathrm{NO}$ production may kill the parasites in the early stages of infection. Thus, it appears that increasing NO production in conjunction with endogenous enzymes can limit the growth of the parasites in the parasitophorous vacuoles of fibrocytes. As fibrocytes are able to rapidly migrate to injured areas and participate in the inflammatory response in various disease states and in vitro observations show that they are able to phagocyte and kill Leishmania, we suggest that fibrocytes are actively involved in the inflammatory response to infection by parasites of the genus Leishmania from the first moments of the infection.

\section{ACKNOWLEDGEMENTS}

To Andrea Henriques Pons and Marcelo Meuser Batista, for their helpful discussions.

\section{REFERENCES}

Abe R, Donnelly SC, Peng T, Bucala R, Metz CN 2001. Peripheral blood fibrocytes: differentiation pathway and migration to wound sites. J Immunol 166: 7556-7562.
Aiba S, Tagami H 1997. Inverse correlation between CD34 expression and proline-4-hydroxylase immunoreactivity on spindle cells noted in hypertrophic scars and keloids. J Cutan Pathol 24: 65-69.

Andersson-Sjöland A, de Alba CG, Nihlberg K, Becerril C, Ramírez R, Pardo A, Westergren-Thorsson G, Selman M 2008. Fibrocytes are a potential source of lung fibroblasts in idiopathic pulmonary fibrosis. Int J Biochem Cell Biol 40: 2129-2140.

Balmelli C, Alves MP, Steiner E, Zingg D, Peduto N, Ruggli N, Gerber H, McCullough K, Summerfield A 2007. Responsiveness of fibrocytes to Toll-like receptor danger signals. Immunobiology 212: 693-699.

Balmelli C, Ruggli N, McCullough K, Summerfield A 2005. Fibrocytes are potent stimulators of anti-virus cytotoxic T cells. J Leukoc Biol 77: 923-933.

Bogdan C, Donhauser N, Döring R, Röllinghoff M, Diefenbach A, Rittig MG 2000. Fibroblasts as host cells in latent leishmaniasis. J Exp Med 191: 2121-2130.

Bucala R 2008. Circulating fibrocytes: cellular basis for NSF. $J$ Am Coll Radiol 5: 36-39.

Bucala R, Spiegel LA, Chesney J, Hogan M, Cerami A 1994. Circulating fibrocytes define a new leukocyte subpopulation that mediates tissue repair. Mol Med 1: 71-81.

Burchmore RJ, Barrett MP 2001. Life in vacuoles-nutrient acquisition by Leishmania amastigotes. Int J Parasitol 31: 1311-1320.

Chesney J, Bacher M, Bender A, Bucala R 1997. The peripheral blood fibrocyte is a potent antigen-presenting cell capable of priming naive T cells in situ. Proc Natl Acad Sci USA 94: 6307-6312.

Chesney J, Metz C, Stavitsky AB, Bacher M, Bucala R 1998. Regulated production of type I collagen and inflammatory cytokines by peripheral blood fibrocytes. J Immunol 160: 419-425.

Côrte-Real S, Grimaldi Jr G, de Meirelles MNL 1988. Leishmania mexicana amazonensis: heterogeneity in 5'-nucleotidase and peroxidase activities of mononuclear phagocytes during in vivo and in vitro infection. Mem Inst Oswaldo Cruz 83: 113-121.

Cunningham AC 2002. Parasitic adaptive mechanisms in infection by Leishmania. Exp Mol Pathol 72: 132-141. 
de Almeida MC, Vilhena V, Barral A, Barral-Netto M 2003. Leishmanial infection: analysis of its first steps. A Review. Mem Inst Oswaldo Cruz 98: 861-870.

Diefenbach A, Schindler H, Röllinghoff M, Yokoyama WM, Bogdan C 1999. Requirement for type 2 NO synthase for IL-12 signaling in innate immunity. Science 284: 51-55.

Field JJ, Burdick MD, DeBaun MR, Strieter BA, Liu L, Mehrad B, Rose Jr CE, Linden J, Strieter RM 2012. The role of fibrocytes in sickle cell lung disease. PLOS ONE 7: e33702.

Garibaldi BT, D’Alessio FR, Mock JR, Files DC, Chau E, Eto Y, Drummond MB, Aggarwal NR, Sidhaye V, King LS 2013. Regulatory T-cells reduce acute lung injury fibroproliferation by decreasing fibrocyte recruitment. Am J Respir Cell Mol Biol 48: 35-43.

Gontijo B, de Carvalho ML 2003. American cutaneous leishmaniasis. Rev Soc Bras Med Trop 36: 71-80.

Grab DJ, Lanners H, Martin LN, Chesney J, Cai C, Adkisson HD, Bucala R 1999. Interaction of Borrelia burgdorferi with peripheral blood fibrocytes, antigen-presenting cells with the potential for connective tissue targeting. Mol Med 5: 46-54.

Grab DJ, Salem ML, Dumler JS, Bucala R 2004. A role for the peripheral blood fibrocyte in leishmaniasis? Trends Parasitol 20: 12.

Hespanhol RC, Soeiro MNC, Meuser MB, Meirelles MNSL, CôrteReal S 2005. The expression of mannose receptors in skin fibroblast and their involvement in Leishmania (L.) amazonensis invasion. J Histochem Cytochem 53: 35-44.

Ishida Y, Kimura A, Kondo T, Hayashi T, Ueno M, Takakura N, Matsushima K, Mukaida N 2007. Essential roles of the CC chemokine ligand 3-CC chemokine receptor 5 axis in bleomycin-induced pulmonary fibrosis through regulation of macrophage and fibrocyte infiltration. Am J Pathol 170: 843-854.

Kisseleva T, von Köckritz-Blickwede M, Reichart D, McGillvray SM, Wingender G, Kronenberg M, Glass CK, Nizet V, Brenner DA 2011. Fibrocyte-like cells recruited to the spleen support innate and adaptive immune responses to acute injury or infection. J Mol Med 89: 997-1013.

Kuroda K, Tajima S 2004. HSP47 is a useful marker for skin fibroblasts in formalin-fixed, paraffin-embedded tissue specimens. $J$ Cutan Pathol 31: 241-246.

Laskay T, van Zandbergen G, Solbach W 2003. Neutrophil granulocytes - Trojan horses for Leishmania major and other intracellular microbes. Trends Microbiol 11: 210-214.

Liese J, Schleicher U, Bogdan C 2008. The innate immune response against Leishmania parasites. Immunobiology 213: 377-387.

Lodge R, Diallo TO, Descoteaux A 2006. Leishmania donovani lipophosphoglycan blocks NADPH oxidase assembly at the phagosome membrane. Cell Microbiol 8: 1922-1931.

Moore BB, Thannickal VJ, Galen B 2005. Bone marrow-derived cells in the pathogenesis of lung fibrosis. Curr Respir Med Rev 1: 69-76.

Mukbel RM, Patten JR C, Gibson K, Ghosh M, Petersen C, Jones DE 2007. Macrophage killing of Leishmania amazonensis amastigotes requires both nitric oxide and superoxide. Am J Trop Med Hyg 76: 669-675.

Naderer T, McConville MJ 2008. The Leishmania-macrophage interaction: a metabolic perspective. Cell Microbiol 10: 301-318.

Nihlberg K, Larsen K, Hultgårdh-Nilsson A, Malmström A, Bjermer L, Westergren-Thorsson G 2006. Tissue fibrocytes in patients with mild asthma: a possible link to thickness of reticular basement membrane? Respir Res 29: 50.

Noben-Trauth N, Lira R, Nagase H, Paul WE, Sacks DL 2003. The relative contribution of IL-4 receptor signaling and IL-10 to susceptibility to Leishmania major. J Immunol 170: 5152-5158.
Opperdoes FR, Coombs GH 2007. Metabolism of Leishmania: proven and predicted. Trends Parasitol 23: 149-158.

Peng H, Herzog EL 2012. Fibrocytes: emerging effector cells in chronic inflammation. Curr Opin Pharmacol 12: 491-496.

Peters C, Aebischer T, Stierhof YD, Fuchs M, Overath P 1995. The role of macrophage receptors in adhesion and uptake of Leishmania mexicana amastigotes. J Cell Sci 108: 3715-3724.

Pilling D, Buckley CD, Salmon M, Gomer RH 2003. Inhibition of fibrocyte differentiation by serum amyloid P. J Immunol 171: $5537-5546$.

Pilling D, Fan T, Huang D, Kaul B, Gomer RH 2009. Identification of markers that distinguish monocyte-derived fibrocytes from monocytes, macrophages and fibroblasts. PLOS ONE: e7475.

Pilling D, Tucker NM, Gomer RH 2006. Aggregated IgG inhibits the differentiation of human fibrocytes. J Leukoc Biol 79: 1242-1251.

Portillo JA, Feliciano LM, Okenka G, Heinzel F, Subauste MC, Subauste CS 2012. CD40 and tumour necrosis factor- $\alpha$ co-operate to up-regulate inducible nitric oxide synthase expression in macrophages. Immunology 135: 140-150.

Quan TE, Cowper S, Wu SP, Bockenstedt LK, Bucala R 2004. Circulating fibrocytes: collagen-secreting cells of the peripheral blood. Int J Biochem Cell Biol 36: 598-606.

Reilkoff RA, Bucala R, Herzog EL 2011. Fibrocytes: emerging effector cells in chronic inflammation. Nat Rev Immunol 11: 427-435.

Rogers ME, Ilg T, Nikolaev AV, Ferguson MA, Bates PA 2004. Transmission of cutaneous leishmaniasis by sand flies is enhanced by regurgitation of fPPG. Nature 430: 463-467.

Rosado JD, Rodriguez-Sosa M 2011. Macrophage migration inhibitory factor (MIF): a key player in protozoan infections. Int J Biol Sci 7: 1239-1256.

Sacks DL, Hieny S, Sher A 1985. Identification of cell surface carbohydrate and antigenic changes between noninfective and infective developmental stages of Leishmania major promastigotes. J Immunol 135: 564-569.

Schmidt M, Sun G, Stacey MA, Mori L, Mattoli S 2003. Identification of circulating fibrocytes as precursors of bronchial myofibroblasts in asthma. J Immunol 171: 380-389.

Scholten D, Reichart D, Paik YH, Lindert J, Bhattacharya J, Glass CK, Brenner DA, Kisseleva T 2011. Migration of fibrocytes in fibrogenic liver injury. Am J Pathol 179: 189-198.

Späth GF, Lye LF, Segawa H, Sacks DL, Turco SJ, Beverley SM 2003. Persistence without pathology in phosphoglycan-deficient Leishmania major. Science 301: 1241-1243.

Ueno N, Wilson ME 2012. Receptor-mediated phagocytosis of Leishmania: implications for intracellular survival. Trends Parasitol 28: $335-344$

von Stebut E 2007. Immunology of cutaneous leishmaniasis: the role of mast cells, phagocytes and dendritic cells for protective immunity. Eur J Dermatol 17: 115-122.

von Stebut E, Belkaid Y, Nguyen B, Wilson M, Sacks DL, Udey MC 2002. Skin-derived macrophages from Leishmania major-susceptible mice exhibit interleukin-12 and interferon-gamma-independent nitric oxide production and parasite killing after treatment with immunostimulatory DNA. J Invest Dermatol 119: 621-628.

Wanasen N, MacLeod CL, Ellies LG, Soong L 2007. L-arginine and cationic amino acid transporter $2 \mathrm{~B}$ regulate growth and survival of Leishmania amazonensis amastigotes in macrophages. Infect Immun 75: 2802-2810.

Wang JF, Jiao H, Stewart TL, Shankowsky HA, Scott PG, Tredget EE 2007. Fibrocytes from burn patients regulate the activities of fibroblasts. Wound Repair Regen 15: 113-121. 